\title{
Impact of Social Media on Current Medical Conferences
}

Jennifer An-Jou Lin, MD ${ }^{1}$ Angela Ting-Wei Hsu, MD ${ }^{1,2}$ Jung-Ju Huang, MD ${ }^{1}$

Bassem W. Daniel, MD, MSc ${ }^{1}$ Che-Hsiung Lee, MD ${ }^{1}$ Soo-Ha Kwon, MD ${ }^{1}$

Evelyn Ting-Hsuan Tang, MD ${ }^{1,2}$ Cheng-Feng Chu, MD ${ }^{1}$ Cheng-An Tony Chien, MS, BS 3

David Chwei-Chin Chuang, MD ${ }^{1}$ Johnny Chuieng-Yi Lu, MD ${ }^{1}$ Isao Koshima, MD ${ }^{4}$ Zeng-Tao Wang, MD ${ }^{5}$

Liwen Hao, MD ${ }^{5}$ Chao Chen, MD ${ }^{5}$ Tommy Nai-Jen Chang, MD ${ }^{1}$

${ }^{1}$ Department of Plastic and Reconstructive Surgery, Linkou Medical Center and Chang Gung Medical College and Chang Gung University,

Chang Gung Memorial Hospital, Taoyuan, Taiwan

${ }^{2}$ Department of Medicine, Mackay Medical College, New Taipei City,

Taiwan

${ }^{3}$ Department of Medicine, Kaohsiung Medical University, Kaohsiung City,

Taiwan

${ }^{4}$ International Center for Lymphedema, Hiroshima University

Hospital, Hiroshima, Japan

${ }^{5}$ Department of Hand and Foot Surgery, Shangdong Provincial

Hospital affiliated to Shangdong University, Shandong, China

J Reconstr Microsurg 2019;35:452-461.
Address for correspondence Tommy Nai-Jen Chang, MD, Division of Reconstructive Microsurgery, Department of Plastic and

Reconstructive Surgery, Chang Gung Memorial Hospital, No. 5,

Fu-Hsing Street, Kwei-Shan, Taoyuan 33305, Taiwan

(e-mail: tommynjchang@yahoo.com.tw).

\begin{abstract}
Keywords

- social media

- Facebook

- international microsurgery club

- medical education

- brachial plexus

- international course on super microsurgery
\end{abstract}

Background Medical conferences are forums for research, continuing medical education, and networking. Social media is increasingly used for communication and networking due to its low cost and ability to overcome large distances. This study investigates the impact that social media brings to the current conference system.

Methods There are three parts of this study: (1) comparing two similar brachial plexus injuries (BPIs) courses without (2009) and with (2017) social media support, and the participants' feedback; (2) sharing our experiences in the management of the 2018 International Course on SuperMicrosurgery (ICSM) conference; and (3) evaluating the studies from the social media platform International Microsurgery Club (IMC), for the consensus pertaining to social media and conference system.

Results With the help of social media, international attendance increased during the $2017 \mathrm{BPI}$ conference compared with the 2009 BPI course ( 25 nationalities in 2009 vs. 35 in 2017). At least $23 \%$ obtained their meeting information through social media. Live surgery was the overall main attraction (79\%). The 2018 ICSM meeting revealed that video posts increased attendance; videos that were the most effective in attracting (viewership) were either short or pertained to surgical procedures. Facebook, Messenger, and WeChat smartphone applications were effective for immediate communication and troubleshooting among the participants. From the IMC polls, 78\% believe that the social media and the conference complemented each other. $97 \%$ attended the conference to update their skills and knowledge.

(1Dr. Kwon's ORCID ID is http://orcid.org/0000-0002-1610-8425.

received

October 2, 2018

accepted after revision

December 9, 2018

published online

February 13, 2019
Copyright $\odot 2019$ by Thieme Medical

Publishers, Inc., 333 Seventh Avenue, New York, NY 10001, USA. Tel: +1(212) 584-4662.
DOI https://doi.org/ 10.1055/s-0039-1677765. ISSN 0743-684X. 
Conclusion Social media is a quick and economic tool in promoting medical conferences and instant messenger systems offer immediate communication amongst associates. Despite the popularity of social media, the conference still has its irreplaceable role. The combination of the conference and the social media enhances the training and education of microsurgeons.

Medical conferences play a major role for professionals in continuing their education. ${ }^{1}$ They provide unique learning resources and career-building opportunities, such as selfpromotion and face-to-face interaction with the hosts and experts. ${ }^{2}$ However, time consumption and high costs may limit participants. Furthermore, the increasing amount of conferences makes it difficult for professionals to select quality meetings. In recent years, the ubiquity of the internet and social media are dramatically changing the learning habits of medical professionals. Online platforms, such as customized websites, Facebook, Twitter, and LinkedIn have become popular for medical education. ${ }^{3-6}$ Facebook, in particular, is the largest social media platform with more than 2 billion users since 2017, and has been one of the best online forums for professional interaction. ${ }^{7}$ Its "Facebook Group" and "Facebook fan" pages can potentially be effective forums for gathering global professionals in different fields.

International Microsurgery Club (IMC), established by the senior author Dr. Tommy Nai-Jen Chang (Taiwan) on May 6, 2016, is based on Facebook and is now the biggest online microsurgery platform in the world, with over 10,000 members in 2.5 years after establishment. IMC provides abundant useful professional information, including case discussions, research collaborations, conference information, related product introductions and other educational resources. ${ }^{8-12}$ IMC also provides links to many other platforms, such as a Facebook fan page, a customized website, and an instant Messenger group for individual meetings in a clear, organized, and interactive manner.

Since conferences and social media platforms are both major learning systems for professionals, it may prove valuable to take a detailed look at how they can work together to promote learning. In June 2017, the organizers of the ninth Congress of the World Society Reconstructive Microsurgery (WSRM) held in Korea created a Facebook fan page that provided general information, conference schedules, recommendations from international masters, local tour information, and local cultural events (https://www.facebook.com/wsrm2017/). All the posts were shared to the IMC by the organizers, mainly by Dr. JoonPio Hong. These links allowed all the participants to communicate regardless of location or time. The real-time information shared during the conference was successful and the conference achieved a record largest number of participants in history (more than 1,300 participants from 72 countries) with a very high satisfactory rate. ${ }^{13}$

After organizing events (the 2009 and 2017 Instructional courses for Adult Brachial Plexus Injuries [BPI courses] and the 2018 International Course on SuperMicrosurgery [ICSM]) and social media platforms (the IMC Facebook fan page, the 2017 BPI Facebook fan page, and the 2018 ICSM Facebook fan page), we analyzed our own resources and examined how social media contributed to each project to answer the questions: (1) how did the social media affect the conference promotion?; (2) how many associates could be reached by social media posts?; (3) what type of content attracts the viewers most?; (4) does promotion through social media significantly attract more participants?; (5) what is the role of instant messenger system?; (6) what are the reasons for and obstacles to attending the real conference?.

\section{Methods}

\section{9 and 2017 Instructional Courses for Adult BPI (BPI Courses)}

These two conferences were hosted by professor D.C.C.C. and his team belonging to the Division of Reconstructive Microsurgery, Department of Plastic and Reconstructive Surgery at the Chang-Gung Memorial Hospital, Linkou Medical Center, Taiwan. ${ }^{14,15}$

The two courses had a nearly identical program including eight live surgeries, lectures, and question and answer panels. The main difference was without (2009) or with (2017) social medial promotion. In 2017, 15 months prior to the BPI course, a customized Facebook fan page "2017 2nd Instructional Course of Adult BPI" (https://www.facebook.com/2017BPI/) was established by Dr. T.N.J.C. for the conference promotion. Information introducing the faculty and the host centers were posted. Educational resources were also regularly shared on the page, offering both basic and advanced understandings of adult brachial plexus injury and its therapy. All the posts on the page were crossposted to IMC. This Facebook fan page was not only open to the meeting participants but also to any of the public who were interested.

The contents of the courses and the demographics of the participants were compared. The participants in the $2017 \mathrm{BPI}$ course were asked to fill out a questionnaire using Google Survey during the conference. The questions were related to the satisfaction of the conference and the idea related to the social media promotion.

\section{International Course on ICSM Meeting}

In 2018, we organized the international promotion of ICSM meeting in Jinan, China, organized by professor Isao Koshima and Zeng-Tao Wang. The international promotion throughout the social media was similar to that of the 2017 BPI meeting, including the customized Facebook fan page (https://www.facebook.com/2018icsm/) established by Dr. T.N.J.C. for the conference promotion, 7 months prior the conference. Information introducing the faculty and the host centers were posted. Educational resources provided by the 
faculties were also regularly shared on the page, offering both basic and advanced understandings of supermicrosurgery. All the posts on the page were cross posted to IMC and the official website (https://www.2018icsm.com/) as well. The domestic (Chinese) promotion was via a customized Application based on Yi-Hui-Bao system (http:// mobile.medmeeting.com/?fbclid=IwAR0Occ6WX3h4FmcoRYWwXJzxUSt2GrzTyZk0HWLwAuRbBTEDbIokGnXSUSg\#/ $\mathrm{mw} / 778 \&$ appinstall $=0$ ). In addition, online messenger groups were created for communication between core members, faculty, and participants on Facebook messenger (English speakers), WeChat (Mandarin/English speakers in different groups), and QQ (Mandarin speakers).

\section{International Microsurgery Club}

Polls for the general consensuses of the current conference system were constructed. Three questions raised in the polls by Dr. T.N.J.C.:

-What's your view about the impact of social media on the conference system?

- What made you decide to attend the conference? (Multiple choices)

- What is your main financial source for the conference?

Also, we collected and analyzed the promotional posts of conferences in IMC between May 6, 2016 and Feb 27, 2018 to understand the platform's impact on the conference system and how global microsurgeons and conference organizers use it. Because most of the members in IMC are plastic or orthopaedic surgeons, the conferences promoted in the group included not only microsurgery conferences but also in areas other than microsurgery (e.g., aesthetic surgery conferences).

\section{Results}

\section{9 and 2017 Instructional Courses for Adult Brachial Plexus Injuries}

The total participants in the 2009 and the 2017 BPI courses were 133 and 126, respectively, with no repeat participants. Compared with the 2009 BPI course, the 2017 BPI course was promoted to more countries (25 in 2009 vs. 35 in 2017) and had a greater proportion of international attendees (73.7 and $84.9 \%, p=0.026)$. The average flight distance to Taiwan increased significantly $(4,418 \pm 3,767$ and $6,627 \pm 3,830 \mathrm{~km}$, $p<0.001$ ). The number of domestic (Taiwan) participants dropped from $35(26.3 \%)$ to 19 (15.1\%) and participants from East Asia greatly decreased (29.3\% to $10.3 \%$ ). On the contrary, participants from West Asia and North America increased by $1.5 \%$ to $9.5 \%(p=0.004)$ and $0.8 \%$ to $7.1 \%(p=0.008)$, respectively (- Table 1 and $\boldsymbol{-}$ - Fig. $\mathbf{1}$ ).

A total of 100 participants responded to the questionnaire for the 2017 course, with a response rate of $79.4 \%$. Among the respondents, $39 \%$ received the meeting information through traditional promotion methods via official website $(22 \%)$, email invitation (11\%), and paper flyers (6\%); $23 \%$ through social media tools including the Facebook fan page (11\%) and IMC (12\%); and 37\% received their information through colleagues. Obtaining the information from colleagues could
Table 1 Comparison of the 2009 and 2017 BPI instructional course members. Classification of the global region is according to the United Nations

\begin{tabular}{|c|c|c|c|}
\hline & 2009 & 2017 & p-Value \\
\hline \multicolumn{4}{|c|}{ General information } \\
\hline Date & $\begin{array}{l}\text { November } \\
10 \text { and } 11\end{array}$ & $\begin{array}{l}\text { November } \\
13-16\end{array}$ & \\
\hline Program & $\begin{array}{l}\text { Eight live } \\
\text { surgeries } \\
\text { Lectures } \\
Q \text { and A panel }\end{array}$ & $\begin{array}{l}\text { Eight live } \\
\text { surgeries } \\
\text { Lectures } \\
\text { Q and A panel }\end{array}$ & \\
\hline $\begin{array}{l}\text { Registration } \\
\text { fee (USD) }\end{array}$ & 400 & 800 & \\
\hline \multicolumn{4}{|l|}{ Faculties } \\
\hline $\begin{array}{l}\text { Domestic } \\
\text { (live surgery) }\end{array}$ & $7(3)$ & $8(4)$ & \\
\hline $\begin{array}{l}\text { International } \\
\text { (live surgery) }\end{array}$ & $4(2)$ & $8(5)$ & \\
\hline \multicolumn{4}{|l|}{ Participants } \\
\hline Countries & 25 & 35 & \\
\hline International & $98(73.7 \%)$ & $107(84.9 \%)$ & $0.026^{*}$ \\
\hline Domestic & $35(26.3 \%)$ & $19(15.1 \%)$ & \multirow[t]{2}{*}{$0.026^{*}$} \\
\hline Total & 133 & 126 & \\
\hline \multicolumn{4}{|l|}{ Subregions } \\
\hline Taiwan & $35(26.3 \%)$ & $19(15.1 \%)$ & $0.026^{*}$ \\
\hline E Asia & $39(29.3 \%)$ & $13(10.3 \%)$ & $<0.001^{*}$ \\
\hline SE Asia & $23(17.3 \%)$ & $31(24.6 \%)$ & 0.148 \\
\hline S Asia & $7(5.3 \%)$ & $10(7.9 \%)$ & 0.358 \\
\hline C Asia & $0(0 \%)$ & $1(0.8 \%)$ & 0.303 \\
\hline W Asia & $2(1.5 \%)$ & $12(9.5 \%)$ & $0.004^{*}$ \\
\hline Oceania & $4(3.0 \%)$ & $8(6.3 \%)$ & 0.201 \\
\hline E Europe & $2(1.5 \%)$ & $0(0 \%)$ & 0.167 \\
\hline W Europe & $8(6.0 \%)$ & $8(6.3 \%)$ & 0.911 \\
\hline S Europe & $1(0.8 \%)$ & $3(2.4 \%)$ & 0.288 \\
\hline N Europe & $8(8.0 \%)$ & $7(5.6 \%)$ & 0.874 \\
\hline N Africa & $0(0 \%)$ & $2(1.6 \%)$ & $\mathrm{N} / \mathrm{A}$ \\
\hline W Africa & $1(0.8 \%)$ & $0(0 \%)$ & $\mathrm{N} / \mathrm{A}$ \\
\hline N America & $1(0.8 \%)$ & $9(7.1 \%)$ & $0.008^{*}$ \\
\hline C America & $0(0 \%)$ & $1(0.8 \%)$ & 0.303 \\
\hline S America & $2(1.5 \%)$ & $2(1.6 \%)$ & 0.957 \\
\hline $\begin{array}{l}\text { Average } \\
\text { flight distance } \\
\text { to Taiwan }(\mathrm{km})\end{array}$ & $4,418 \pm 3,767$ & $6,627 \pm 3,830$ & $<0.001^{*}$ \\
\hline
\end{tabular}

Abbreviations: A, answer; BPI, brachial plexus injuries; C, central; E, east; N/A, not applicable; N, north; Q, question; S, south; USD, U.S. dollar; W, west. ${ }^{*} p$-Value $<0.05$.

be a "gray area" because the original source of information is untraceable (-Fig. 2A, 2B).

According to the participants' responses, the main reason for joining the 2017 BPI course was live surgery (79\%), followed by strong cast (45\%), and good reputation of the organizers (44\%). Most participants who used the Facebook fan page and IMC were satisfied with our online service of 


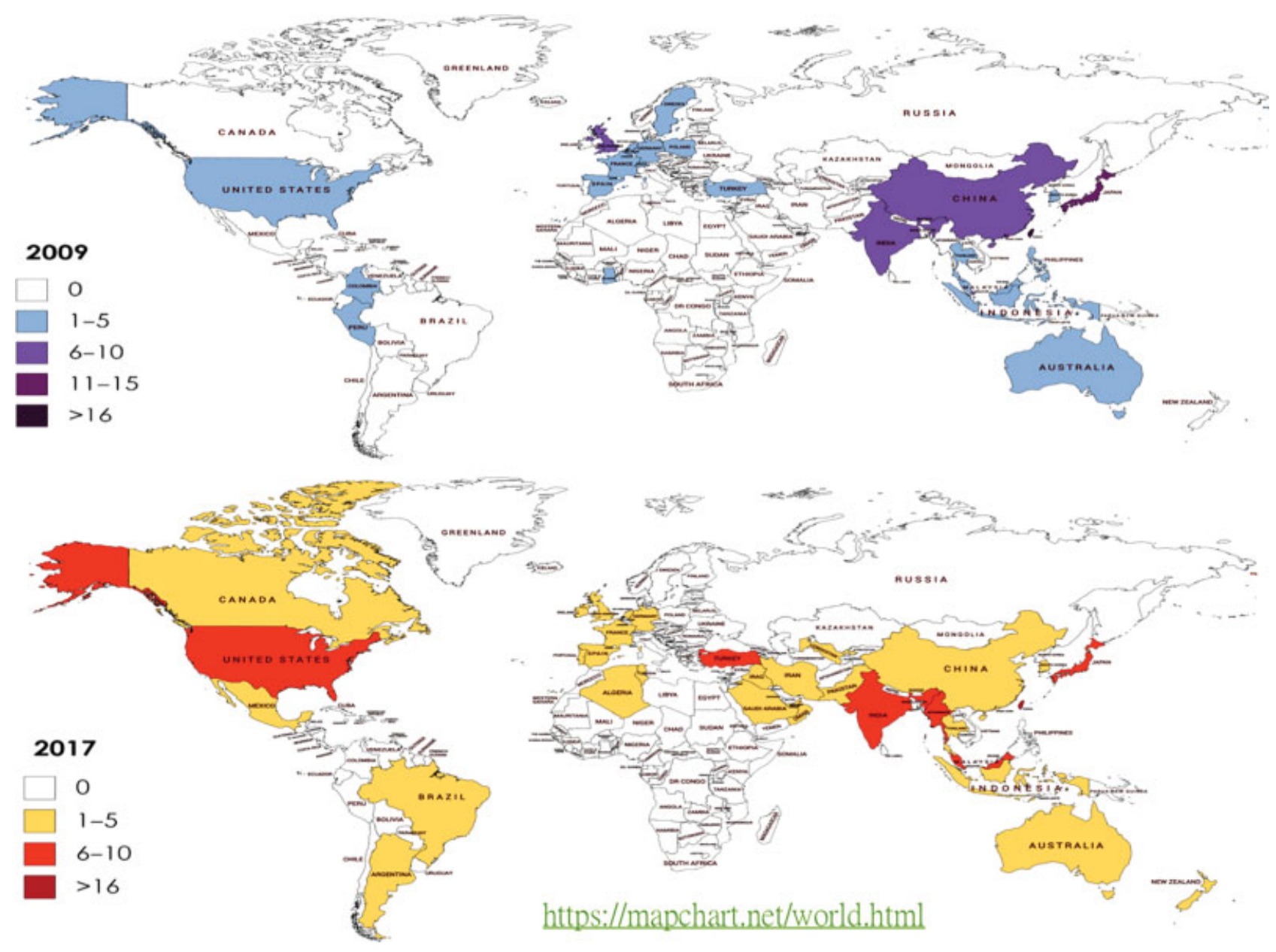

Fig. 1 The distribution of the participants between the 2009 and 2017 BPI meetings. In, 2009, when there was no social media used for promotion, the participants mostly came from nearby countries due to limited dissemination of information. In 2017 , when social media became a major tool for promotion, participants were not limited by time and distance. BPI, brachial plexus injuries.
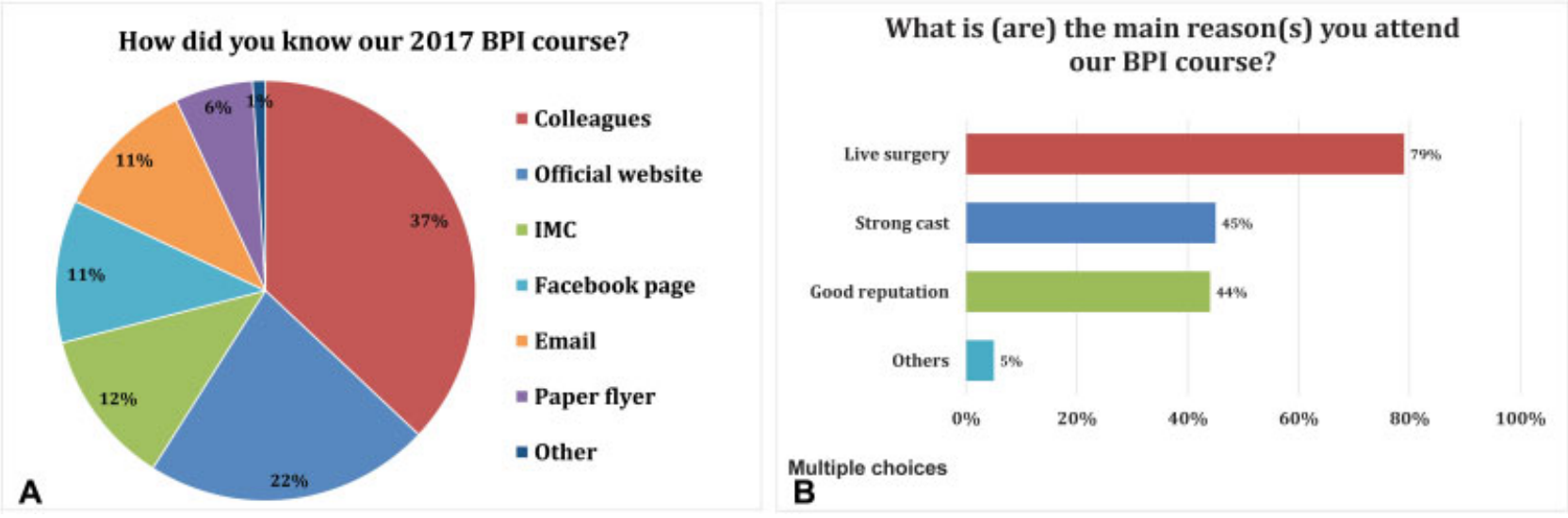

Fig. 2 (A) Survey results from the participants of the $2017 \mathrm{BPI}$ instructional course $(n=100)$. At least $23 \%$ people received information for the conference via social media networks (IMC + 2017 BPI fan page). (B) Survey results from the participants of the $2017 \mathrm{BPI}$ instructional course $(n=100)$. Conference attraction points are shown. Live surgery was the most attractive category, followed by strong cast and good reputation of the organizers. BPI, brachial plexus injuries; IMC, international microsurgery club.

troubleshooting and clear information. In total, $88 \%$ of repliers described the experience with our service as either "very satisfied" or "satisfied."

Our 2017 BPI Facebook fan page insights showed that there were 1,271 followers from 48 countries by the end of the 2017 course (November 16, 2017). There were total 78 official posts including 10 videos and 68 photo/words/link information. The videos posted on the Facebook fan group were investigated and analyzed. An informative video can reach $3,022 \pm 2,360$ (range: $1,200-8,400$ ) people with 
Table 2 Number of people reached and the number of views for the videos posted on the Facebook fan page

\begin{tabular}{|l|l|l|l|}
\hline Date & Title & $\begin{array}{l}\text { Amount } \\
\text { of views }\end{array}$ & $\begin{array}{l}\text { People } \\
\text { reached }\end{array}$ \\
\hline Aug 11,2016 & $\begin{array}{l}\text { First announcement } \\
\text { of the BPI course }\end{array}$ & 1,900 & 4,000 \\
\hline Aug 11, 2016 & $\begin{array}{l}\text { The detail of } \\
\text { the program }\end{array}$ & 1,400 & 2,400 \\
\hline May 30, 2017 & $\begin{array}{l}\text { Prof. Chuang's } \\
\text { welcome message }\end{array}$ & 2,100 & 8,300 \\
\hline July 31, 2017 & $\begin{array}{l}\text { Introduction of } \\
\text { the BPI course }\end{array}$ & 1,000 & 4,500 \\
\hline
\end{tabular}

Abbreviation: BPI, brachial plexus injuries.

Note: There were a total of 1,271 followers from 48 countries until the end the $2017 \mathrm{BPI}$ course (Nov 16, 2017). An informative video usually can reach $2,400-8,300$ people and $1,000-2,100$ views around the world.

$820 \pm 866$ (range: $242-1,900$ ) views. The peaks of viewing times and online interactions (thumbs up, comments, or sharing the post) were within 1 to 2 days after the post. The members of the group can review and interact with any posts at any time because all the posts are remained on the page (-Table 2).

\section{International Course on Super Microsurgery (ICSM) Meeting}

The total international online registrations of the 2018 ICSM were 143 people but only 58 attended the conference. We supposed the main reason that some of the participants could not make it because of the VISA issues. We had a very diverse population of participants $(n=58), 36$ were from Asia and Oceania, 10 from Europe, 7 from Africa, and 6 from America.
Our 2018 ICSM Facebook fan page showed that there were 906 followers from 45 countries by the end of the meeting (October 15, 2018). our previous experiences showed that video posts attract a larger audience than posts that contained information other than videos (i.e., text, photos, shared information). As such, we added more video posts in 2018 ICSM Facebook fan page. There was a total of 96 official posts which included 49 videos and 47 nonvideo posts. An informative video reached 2,928 $\pm 1,837$ (range: 1,154-11,156) people with $1,243 \pm 957$ (range: 413-5,062) views. The top three views of the videos were (1) Dr. Pedro Ciudad's (Peru) welcome talk (11,156 views); (2) Dr. ShanShan Qiu's (the Netherlands) welcome talk (3,559 views); and (3) Dr. Hidehiko Yoshimatsu's (Japan) demonstration of the superficial circumflex iliac artery perforator (SCIP) flap elevation (3,361 views).

The video posts $(n=49)$ were then divided into five types: (1) faculty's invitation (talk only; $n=13$ ); (2) faculty introduction plus expertise demonstration $(n=21)$; (3) surgical demonstration $(n=8)$; (4) conference promotion by central $(n=4)$; (5) special topics $(n=4)$. The video statistics showed that in most videos, the viewer on average of 3 seconds. Videos with audience retention more than 10 seconds tended to be surgical demonstration videos (68.05\% audience retention rate) whereas the talk-only videos had the lowest retention rate $(46.76 \%$ audience retention rate; - Fig. 3) As for the videos' completion rate based on the length, shorter videos had higher completion rate. Videos around 30 seconds in length had only 10 to $30 \%$ completion rate ( - Fig. 4). Overall, the highest completion rate was group 3 (39.2\%), followed by groups 5, 2, 4, and 1 (11.08\%; - Fig. 5 ) In all, the groups, the audiences can only watch around 10 seconds (7.85-11 seconds in groups $1,2,4,5)$, except 19.38 seconds in group 3 (surgical demonstration; - Fig. 6) Also, if we pooled the groups 1 and 2 then compared the talks

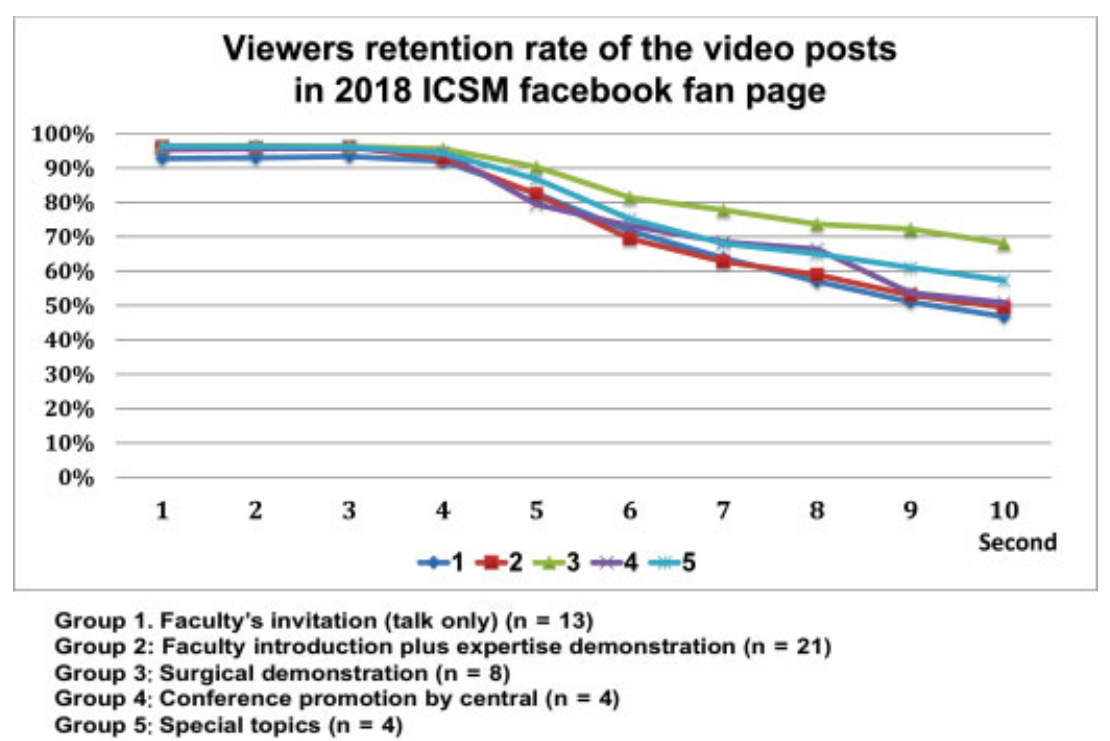

Fig. 3 Survey results of the Facebook fan page video posts for the 2018 ICSM conference based on groups $1-5$ ( $n=13,21,8,4,4$, respectively). Surgical demonstration videos (group 3) retained members the longest (68.05\% up to 10 seconds), followed by special topics (group $5,57.3 \%$ at 10th second). Retention rate for conference promotion (group 4), Faculty's invitation (talk only; group 1), and faculty introduction + expertise demonstration (group 2) were all relatively low (ranging from 46.76-50.85\%). ICSM, International Course on uperMicrosurgery. 


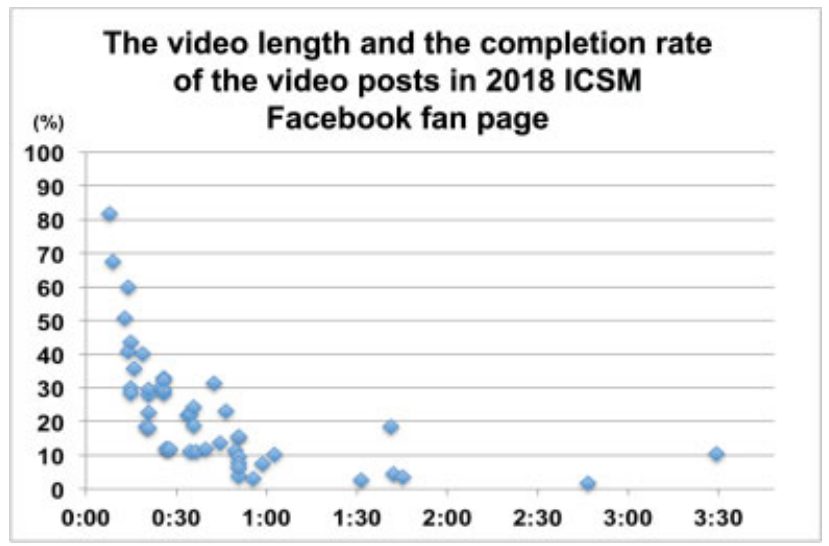

Fig. 4 Comparison of the completion rate of 47 video posts from the 2018 ICSM Facebook fan page based on the length. The shorter of the videos, the higher the completion rate. The audience interest rate dropped very dramatically when the video length exceeded 30 seconds-completion rates were only $10-30 \%$. ICSM, International Course on SuperMicrosurgery.

from male or female faculties, we identified that the videos from female faculties reached more people and attracted more people to watch $(2,490: 4,538$ by reach; $928: 2,177$ by view; - Fig. 7).

Different from most international meetings, instant messenger systems, such as Facebook messenger (English speakers), WeChat (Mandarin speakers), and QQ (Mandarin speakers) played a very important role in this meeting for online discussion, including connection, decision-making, and immediate troubleshooting. This format is very fast, economic and interactive. In this meeting, many issues such as VISA, transportation, and the instant change of the schedule, or any announcement, were delivered through these systems both in Mandarin and English instantly. Since this meeting was held in China, where the Facebook was still blocked, all the faculties and participants were requested to open a WeChat account and joined the group.

\section{International Microsurgery Club}

The polls we conducted on IMC showed that the majority of the microsurgeons $(78 \%, n=51)$ considered social media to be a powerful tool to facilitate the promotion of the conference system. Another $18 \%(n=12)$ reported that social media helped them access information and select qualified conferences more efficiently. Only $4 \%(n=2)$ stated that they attended less conferences than before because it is easy to learn through online sources (-Fig. 8A). Furthermore, 97\% considered "updating and adding knowledge" as the main factor that attracted them to attend the conferences, whereas less than $10 \%$ focused on "the opportunities to try new instruments," "self-promotion," "the casts of the faculty," "meeting friends," "reasonable registration fee," and "good location" (multiple selections, $n=59$; - Fig. 8B). In terms of financial resources, $73 \%$ covered the conference costs by themselves, only $7 \%$ were supported by the institution and the third parties, including scholarships, foundations, internal committees or others. Unfortunately, $15 \%$ were unable to afford the fee for the conferences ( $n=162$; - Fig. 8C).

Between May 6, 2016 and Feb 27, 2018, 333 posts of 108 different microsurgery or related professional scientific meetings were shared in the group. Both the quality and quantity of posts increased over time. Instead of simply attaching a poster or a picture, there are now an increasing number of ways to promote an event and attract the interest of surgeons, whether it is posting short videos of a speaker or

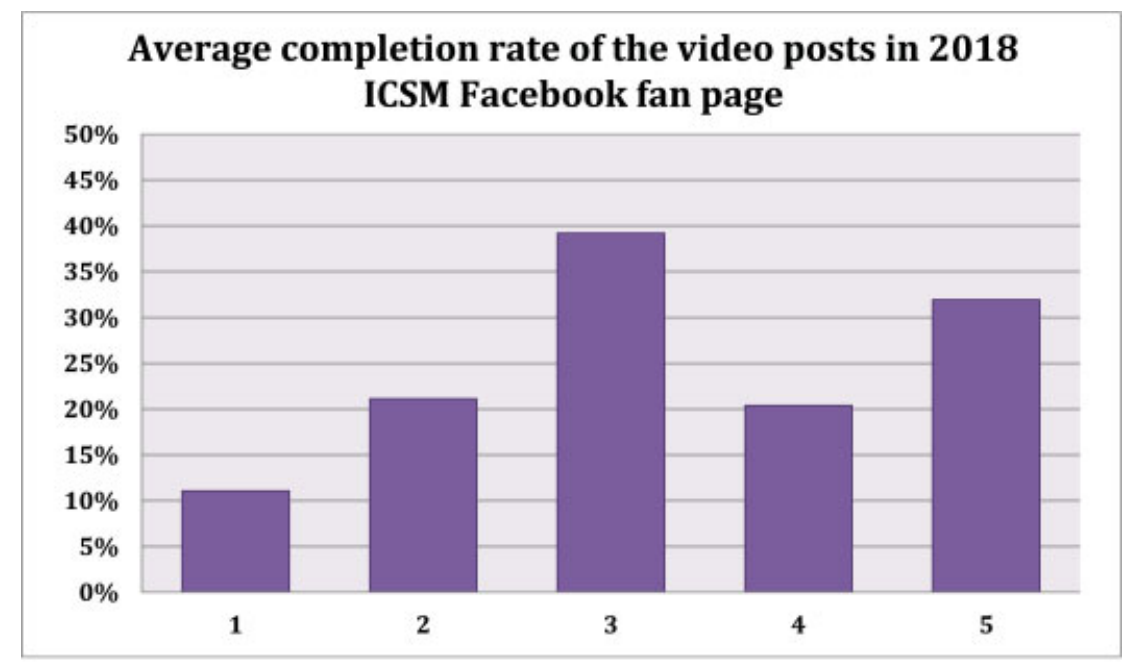

Group 1. Faculty's invitation (talk only) $(n=13)$
Group 2: Faculty introduction plus expertise demonstration $(n=21)$
Group 3: Surgical demonstration $(n=8)$
Group 4: Conference promotion by central $(n=4)$
Group 5: Special topics $(n=4)$

Fig. 5 Comparison of the completion rate of 47 video posts from the 2018 ICSM Facebook fan page based on contents. Surgical demonstration videos (group 3) had the highest completion rate (39.2\%), followed by special topics (group 5). Videos of faculty's invitation had the lowest completion rate (11.08\%). ICSM, International Course on SuperMicrosurgery. 


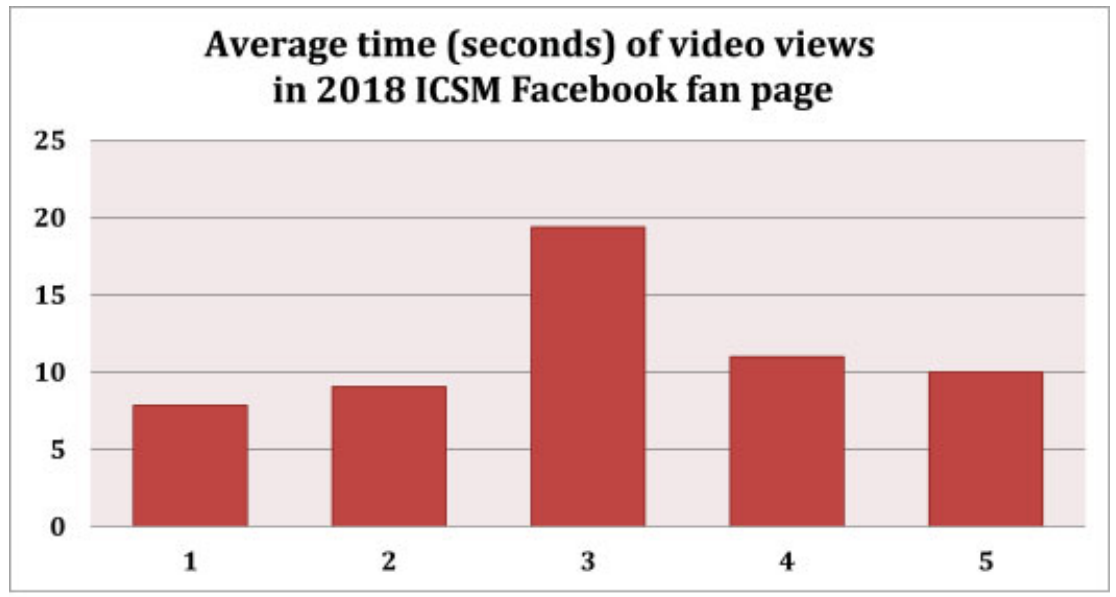

Group 1. Faculty's invitation (talk only) $(n=13)$

Group 2: Faculty introduction plus expertise demonstration $(n=21)$

Group 3: Surgical demonstration $(n=8)$

Group 4: Conference promotion by central $(n=4)$

Group 5: Special topics $(n=4)$

Fig. 6 Comparison of the completion rate of 47 video posts from the 2018 ICSM Facebook fan page based on average viewing time. The Surgical demonstration videos (group 3 ) had the longest view time (19.38 seconds), whereas the others were viewed only half as long, ranging from 7.85-11 seconds.

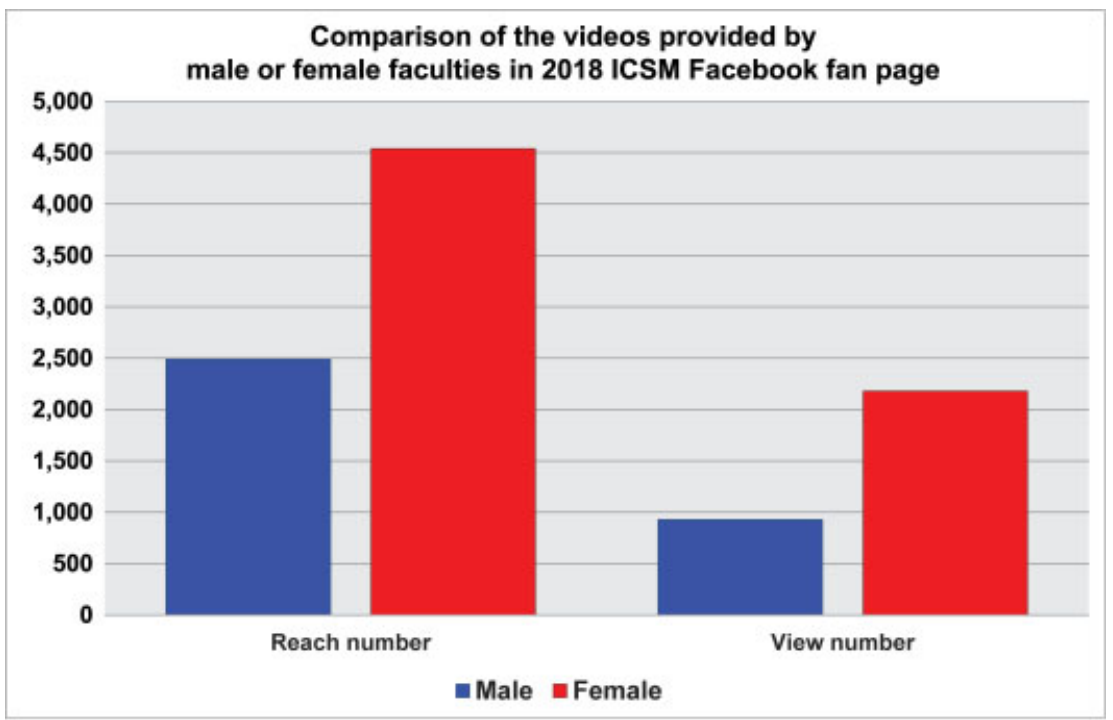

Fig. 7 Comparison of video posts from either male $(n=23)$ or female $(n=3)$ faculties from the 2018 ICSM Facebook fan page. We found that on average, promotion from female faculties reached and were viewed by more people than the videos provided by male faculties $(2,490: 4,538$ by reach; $928: 2,177$ by view). ICSM, International Course on SuperMicrosurgery.

a surgical demonstration, or even a poll for speakers and topics (-Fig. 9).

\section{Discussion}

Social media is a computer-based interactive communication tool that has successfully become main stream in the last decade. In 2018, there are more than 2 billion subscribers on Facebook alone. ${ }^{8,9}$ However, the role of social media in the medical and health care fields is still evolving because it involves legal, ethical, institutional, privacy, and confidentiality restrictions. ${ }^{2,3}$ By following certain ethical guidelines, professionals can safely use this tool. The primary goal of this study was to provide an overview of current concepts related to social media, to evaluate its impact on conferences, and to understand its advantages and limitations. ${ }^{3,16}$

In 2009, when social media was not yet popular, the promotion of our BPI course relied on e-mail, paper flyers, and the official website. All the information posted on the official website was without interaction or feedback. During the course most of the participants were as expected from nearby countries, such as Japan or China due to the difficulties of dispersing information. However, in the 2017 BPI course, the social media had become the major tool for 
A How do you view the impact of social
media on the conference system?

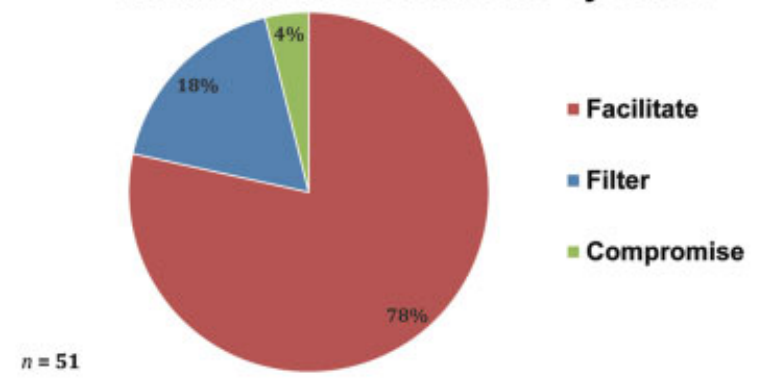

B What made you decide to attend the conference? (Multiple choices)

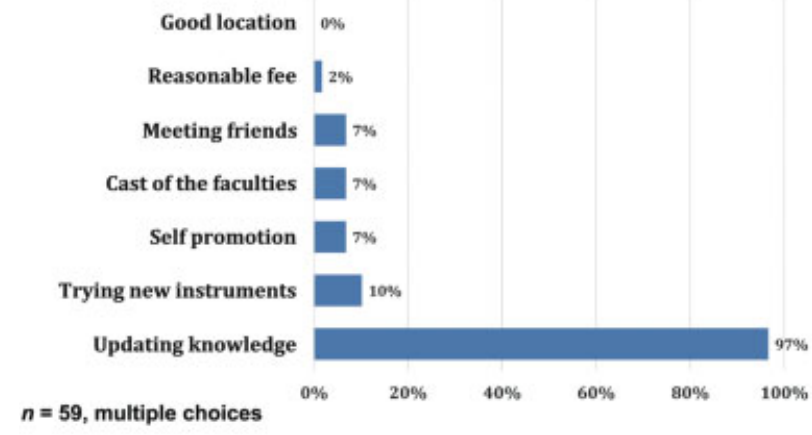

C

What is your main financial source for the conference costs?

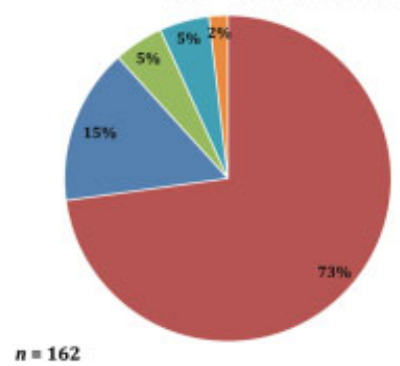

= Self paid

= Can't afford it

- Supported by the institution

= Half self paid / half supported

" Supported by the thired party

Fig. 8 Results of the polls and the statistical insights from the International Microsurgical Club (IMC) regarding social media and thoughts on our conference system. (A) A total of $78 \%$ of the population believed that social media and the conference complement each other if the organizers can provide clearer information, the people are more willing to join. $18 \%$ of the repliers thought the social media can filter the conference if the organizers don't provide unique content the conference may be unsuccessful. (B and C) $97 \%$ of the repliers attend the conference because they want to update their skill and knowledge; however, the financial issue may limit the participants since $73 \%$ of the repliers pay by themselves and $15 \%$ of the repliers cannot afford it.

promotion and therefore, more people received regular updates and could become interested in participating.

The information spread faster and wider through Facebook and IMC than through the conventional methods. Additionally, the internet provided exposure to places afar, such as North Africa, the Middle East, and Latin America. According to our data, the average flight distance was significantly increased compared with that of the 2009 course.
Although the registration fee was doubled from 400 to 800 USD, we still had 126 participants in the 2017 course. The participants did not overlap with that of the 2009 course. The reasons may be because: (1) our BPI course is an "instructional course" for beginners, and there was no major change in the faculties including the operators and lecturers between the two courses; (2) we offered purchasable educational DVDs of the live surgeries from the 2009 BPI course and sold more than 130 copies worldwide between 2010 and 2018. Unfortunately, this widely distributed content was illegally copied.

The Facebook fan page and IMC played an essential role in promoting the 2017 BPI course. However, Facebook is restricted or banned in some countries such as the China, Iran, and North Korea; in these countries, the conference promotion requiring traditional means of official website, paper flyers, and customized social media tools (e.g., WeChat and QQ in China) or websites such as HANDSURGERY (http:// www.handsurgery.cn/), the biggest social media for Chinese microsurgeons. ${ }^{11}$ These experiences helped immensely when we organized 2018 ICSM meeting, we designated two parallel instant messenger systems for conference promotion, online discussion, connection, decision-making, and immediate troubleshooting via Facebook messenger (English speakers), WeChat (Mandarin speakers), and QQ (Mandarin speakers). The instant messenger system is even more efficient for the communication than the Facebook group and Facebook fan page but the main drawback is that important documents are not easily stored and are needed to utilize other systems for information dissemination and preservation.

Promotion format also was of significance. Video posts attracted more people than photo or text posts. If the video was linked to related topics, translated to different languages, or included many people (so more people can be tagged in the video as the promotion), the dissemination of the videos was greatly enhanced, achieving more than 5,000 views. ${ }^{8,10}$ Our data suggested that: (1) usually the audience viewed video for 3 seconds; (2) surgical videos are the most popular type video posts, whereas that of a single person's talk is the least attractive; (3) the longer the video, the less audiences complete the entire video; and (4) female faculty attract larger audiences than male faculty.

Another powerful tool we used that incorporated social media was online questionnaires. In the 2017 BPI course, most of the participants were very satisfied. Participants also provided constructive suggestions from the polling platform, including to assist in promoting several international societies of plastic surgery, orthopaedic surgery, and hand surgery; and pointing out the lack of dietary restrictions (e.g., halal, allergies) and the lack of a Muslim prayer room. These previously unconsidered details will be improved in future conferences to serve participants from different cultures.

The poll on IMC in this study revealed that most members consider social media a useful tool for promoting conferences because of its information dissemination efficiency and interactive character. Moreover, the cost is relatively low compared with traditional methods. Lastly, social media 


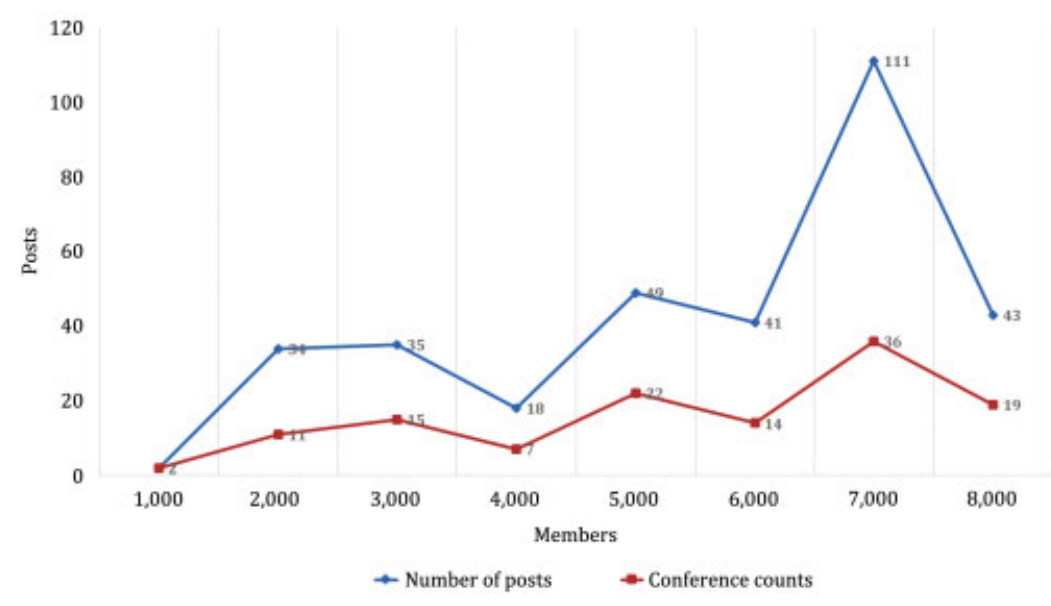

Fig. 9 Number of posts pertaining to the conference on the IMC page. Since the establishment of IMC on May 2016, 107 conferences have been promoted 333 times in total. With the development of the group, there has been an increasing amount of microsurgery conference-related posts in the group.

platforms like IMC have made the global microsurgeons familiar with each other and enhanced their willingness to meet in conferences for further discussions. ${ }^{11}$

With the growing popularity of social media, we believe there will be more opportunities for integration with the conference system. Online meeting systems and live broadcasts of academic events will become more common, providing instant access to knowledge and communication without the limitation of time and distance. This may reduce the need for scholars to spend time and money traveling abroad for conferences. This also paves the way for future conference systems to develop an "audience first strategy" which provides services that carefully meet the needs of participants. The hosts can provide a system, such as a poll that allows the audience to choose topics, to make the conference more interactive and worth their time. This way, the audience, instead of the speakers, can customize the programs. We foresee that social media platforms will play a more supplementary role in large conferences and may even replace smaller ones. ${ }^{9,10}$

\section{Conclusion}

In conclusion, social media is an effective and economic tool for promoting and managing medical conferences. It can gather resources for medical professionals and allows participants and hosts to interact with each other easily. Online promotion through social media plays an important role based on its inherent convenience, and low cost. Video posts can attract more people especially if it pertains to surgical demonstrations, while the core content that attracts the majority of medical professionals to these conferences is still live surgery or cadaveric demonstrations. Despite the convenience and abundance of the information on the internet, the actual medical conferences remain irreplaceable. We believe that combining online platforms with traditional learning materials can enhance professional education and training in not only microsurgery but also all other medical specialties.

Financial Disclosure

None of the authors has financial interests in any of the products, devices, or drugs mentioned in this manuscript.

Conflict of Interest

None declared.

\section{References}

1 Mishra S. Do medical conferences have a role to play? Sharpen the saw. Indian Heart J 2016;68(02):111-113

2 Mishra S. Do we need to change the medical curriculum: regarding the pain of others. Indian Heart J 2015;67(03):187-191

3 Grajales FJ III, Sheps S, Ho K, Novak-Lauscher H, Eysenbach G. Social media: a review and tutorial of applications in medicine and health care. J Med Internet Res 2014;16(02):e13

4 Messaoudi T, Bodin F, Hidalgo Diaz JJ, et al. Evaluation of a new eLearning platform for distance teaching of microsurgery. Chir Main 2015;34(03):109-112

5 Mabvuure NT, Rodrigues J, Klimach S, Nduka C. A cross-sectional study of the presence of United Kingdom (UK) plastic surgeons on social media. J Plast Reconstr Aesthet Surg 2014;67(03): 362-367

6 Chang JB, Woo SL, Cederna PS. Worth the "likes"? the use of facebook among plastic surgeons and its perceived impact. Plast Reconstr Surg 2015;135(05):909e-918e

7 Pander T, Pinilla S, Dimitriadis K, Fischer MR. The use of Facebook in medical education-a literature review. GMS Z Med Ausbild 2014;31(03):Doc33

8 Chang TN, Hsieh F, Wang Z, Kwon S, Lin JA, Tang ET. Social media mediate the education of the global microsurgeons: the experience from International Microsurgery Club. Microsurgery 2018; 38:596-597 
9 Chang TN. Knowledge revolution through online interactive platform: international microsurgery club. Int Microsurg J 2017;1 (02):1-2

10 Kwon SH, Lee $\mathrm{CH}$, Hsu AT, et al. Use of social media and an online survey to discuss complex reconstructive surgery: a case of upper lip reconstruction with 402 responses from international microsurgeons. J Reconstr Microsurg 2018;34(06):413-419

11 Lin JAJ, Omar UF, Mateev M, Chang TN. From virtuality to reality social media facilitates the interaction between global microsurgeons. Int Microsurg J 2017;1(03):2-5

12 Kwon SH, Goh R, Wang ZT, Ting-Hsuan Tang E, Chu CF, Chen YC, Chuieng-Yi Lu J, Wei CY, Ting-Wei Hsu A, Nai-Jen Chang T. Tips for making a successful online microsurgery educational platform: the experience of International Microsurgery Club. Plast Reconstr Surg 2019;143(01):221e-233e

13 Mun GH. Ninth congress of world society for reconstructive microsurgery. Microsurgery 2017;37(08):963-964

14 Chuang DC-C, Wei F-C, Chang TN-J, Lu JC-Y. A great opportunity to meet and learn from peripheral nerve experts. Int Microsurg J 2017;1(02):4

15 Chuang DC-C. Welcome message for the second instructional course on adult brachial plexus injuries. Int Microsurg J 2017;1 (01):3

16 George DR, Rovniak LS, Kraschnewski JL. Dangers and opportunities for social media in medicine. Clin Obstet Gynecol 2013;56 (03):453-462 